\title{
Hepatitis C screening in commercially insured U.S. birth-cohort patients: Factors associated with testing and effect of an EMR-based screening alert
}

\author{
Amoah Yeboah-Korang ${ }^{1}$, Mohammad I. Beigㄹ, Mohammad Q. Khan ${ }^{1}$, \\ Jay L. Goldstein ${ }^{1}$, Don M. Macapinlac ${ }^{1}$, Darryck Maurer ${ }^{1}$, Amnon Sonnenberg ${ }^{2}$, \\ Claus J. Fimmel ${ }^{1}$ \\ 'NorthShore University HealthSystem, Evanston, IL,USA; \\ 2Portland VA Medical Center and Oregon Health \& Science University, Portland, OR, USA
}

Address for Correspondence: Dr. Amoah Yeboah-Korang, NorthShore University HealthSystem, Evanston, IL 60201, USA.

Email: ayeboahkorang@gmail.com

\begin{tabular}{|l|}
\hline Access this article online \\
\hline $\begin{array}{l}\text { Website: } \\
\text { www.intern-med.com }\end{array}$ \\
\hline DOI: \\
10.2478/jtim-2018-0012 \\
\hline Quick Response Code: \\
\hline \\
\\
\\
\\
\\
\end{tabular}

\section{ABSTRACT}

Background and Objectives: Hepatitis C virus (HCV) testing rates among U.S. birth-cohort patients have been studied extensively, limited data exists to differentiate birth-cohort screening from risk- or liver disease-based testing. This study aims to identify factors associated with $\mathrm{HCV}$ antibody (HCV-Ab) testing in a group of insured birth cohort patients, to determine true birth cohort testing rates, and to determine whether an electronic medical record (EMR)driven Best Practice Alert (BPA) would improve birth cohort testing rates. Methods: All birthcohort outpatients between 2010 and 2015 were identified. HCV-Ab test results, clinical, and demographic variables were extracted from the EMR, and factors associated with testing were analyzed by logistic regression. True birth-cohort HCV screening rates were determined by detailed chart review for all outpatient visits during one calendar month. An automated Best Practice Alert was used to identify unscreened patients at the point of care, and to prompt $\mathrm{HCV}$ testing. Screening rates before and after system-wide implementation of the BPA were compared. Results: The historic HCV-Ab testing rate was $11.2 \%(11,976 / 106,753)$. Younger age, female gender, and African American, Asian, or Hispanic ethnicity, and medical comorbidities such as chronic hemodialysis, HIV infection, and rheumatologic and psychiatric comorbidities were associated with higher testing rates. However, during the one-month sampling period, true age cohort-based testing was performed in only 69/10,089 patients $(0.68 \%)$. Following the system-wide implementation of the HCV BPA, testing rates increased from $0.68 \%$ to $10.76 \%(P<0.0001)$. Conclusions: We documented low HCV-Ab testing rates in our baby boomers population. HCV testing was typically performed in the presence of known risk factors or established liver disease. The implementation of an EMR-based HCV BPA resulted in a marked increase in testing rates. Our study highlights current HCV screening gaps, and the utility of the EMR to improve screening rates and population health.

Key words: : hepatitis $\mathrm{C}$, hepatitis $\mathrm{C}$ virus, birth-cohort, screening, baby boomer

\section{INTRODUCTION}

Chronic hepatitis $\mathrm{C}$ virus (HCV) infection is a common cause of death from liver disease, and a leading indication for liver transplantation. ${ }^{[1]}$ An estimated 3.2 million people are living with HCV in the United States. ${ }^{[2]}$ With the new direct-acting antivirals, most $\mathrm{HCV}$-infected patients could potentially be cured of their disease..$^{[3]}$ However, many people living with $\mathrm{HCV}$ infection are unaware of their infection status. $^{[4]}$ As a result, the disease remains under-diagnosed and undertreated.

In 1998, the CDC recommended HCV testing for certain high-risk populations, 
including injection drug users, recipients of transfusions or transplants prior to 1992, patients on hemodialysis, health care and public safety workers with needle stick or mucosal exposure to HCV-infected blood, children born to HCVpositive women, and patients with abnormal liver tests ${ }^{[5]}$. However, risk-based HCV testing was found to miss more than half of all infected persons. Among participants in the NHANES survey, only seven per cent of HCV-infected persons reported having been tested based on known risk factors for $\mathrm{HCV}^{[4]}$ and only $45 \%$ to $85 \%$ of $\mathrm{HCV}$-infected persons had been tested for $\mathrm{HCV} \cdot{ }^{[6-8]}$

Subsequent studies demonstrated a significantly increased prevalence of HCV infection in persons born between 1945 through 1965. This cohort, subsequently named "baby boomers" or birth-cohort, accounts for more than three quarters of all HCV infections and HCV-related deaths in the United States.

Consequently, the CDC recommendations were amended to include $\mathrm{HCV} \mathrm{Ab}$ testing in all birth-cohort patients, in addition to risk-based testing. ${ }^{[9]}$ According to a CDC estimate, the implementation of this recommendation would result in the identification of an additional 800,000 persons who are currently unaware of their HCV status. With proper linkage to care, this measure could prevent more than 120,000 HCV-related deaths. ${ }^{[10]}$ In accordance with the CDC recommendation, the United States Preventive Services Task Force in June 2013 endorsed one-time HCV antibody testing in all birth-cohort patients, regardless of their risk profile. ${ }^{[1]}$

In general, HCV screening rates in birth-cohort patients have remained low. A study of over 25,000 baby boomer patients enrolled in the Kaiser Permanente Mid-Atlantic States' (KPMAS) health system revealed that $14.4 \%$ had been HCV antibody-tested between 2003 and 2012. ${ }^{[12]}$ More recent quality improvement studies reported testing rates of $11 \%$ to $47.2 \% .^{[13,14]}$

Although HCV testing rates among U.S. birth-cohort patients have been studied extensively, limited data exists to differentiate birth-cohort screening from risk- or liver disease-based testing. The aims of our study were to analyze factors associated with overall $\mathrm{HCV}-\mathrm{Ab}$ testing in a large birth-cohort population, to determine true birth-cohort testing rates, and to evaluate the impact of a new EMRbased BPA on HCV screening in our hospital system.

\section{METHODS}

\section{Clinical data extraction}

NorthShore University Health System maintains a database containing demographic and clinical data of its entire patient population. This information is extracted from the health system's electronic medical record system (EPIC). We searched the patient database with regard to patients' HCV test status, and demographic and clinical characteristics. Our study protocol conformed with the World Health Organization's Declaration of Helsinki guidelines. No individual patient information was revealed and patient records were de-identified before being included in the present analysis. For these reasons, the study protocol was exempt from the need for approval by the Institutional Review Board.

Overall HCV testing rates in all NorthShore baby boomer patients (2010-2015) (Study Population 1) This group included all unique baby boomer patients who presented for at least one outpatient visit between January $1^{\text {st }}, 2010$, and December 31 $1^{\text {st }}, 2015$. Charts were searched for HCV test results, retrieving information from as early as 2003. Demographic and clinical variables included the patient's self-assigned ethnic group and race, age, sex, and comorbidities such as HIV, diabetes, psychiatric disease, cancer, and chronic kidney disease.

\section{HCV testing in birth-cohort patients seen in primary care clinics during the month of July, 2015 (Study Population 2)}

A limitation of our analysis of study population 1 was the lack of information regarding the indication for $\mathrm{HCV} \mathrm{Ab}$ testing. In order to determine the true birth-cohort screening rates, we studied a second group of patients consisting of all baby boomer patients presenting for a primary care or subspecialty clinic appointment between July $1^{\text {st }}$ and July $31^{\text {th }}, 2015$. Patients were stratified into internal medicine, family medicine, or "other" subspecialties. For patients with multiple visits during the index month, the first clinic was chosen as the specialty of record. Patients' charts were reviewed to determine whether HCV Ab testing was ordered in the process of evaluating established liver disease ("diagnostic"), a history of risk behaviors ("risk-based"), or solely for birth-cohort screening ("true screening"). Birthcohort HCV screening rates by primary care physicians were compared to those of subspecialists.

We calculated the fraction of test-eligible patients for whom the HCV antibody test was ordered during the one-month time interval. In addition, we determined the fraction of patients who were tested for diagnostic, risk-based, or true screening indications.

\section{Implementation of a HCV Best Practice Alert}

An EPIC alert was designed to identify age cohort patients who had not been previously HCV-tested at our institution. Test-naïve patients were automatically identified at the point of care. A Best Practice Alert (BPA) was generated and 
prominently displayed in the patient's electronic medical record. The BPA prompted the physician to place an order for the HCV antibody, or to forego placing the test at their or the patient's discretion. The BPA was introduced systemwide in July of 2017, and announced to the primary care physicians via electronic communications and in person at various teaching and update meetings. The number of $\mathrm{HCV}$ alerts and resulting HCV antibody tests, and the results of HCV antibody and subsequent confirmatory HCV-RNA testing were tracked, and calculated on a monthly basis.

\section{Statistical analysis}

For the analysis of the first study population, the prevalence of $\mathrm{HCV}-\mathrm{Ab}$ testing was expressed as percentage of all patients in each individual demographic subgroup. Similarly, the prevalence rate was expressed as percentage of all patients with or without various comorbid conditions. Differences in prevalence among categorical variables were compared using chi-square tests or calculating odds ratios (OR) with their 95\% confidence intervals (CI). In a multivariate analysis, using logistic regression, the occurrence of HCV antibody testing served as the outcome variables. Demographic characteristics and various comorbidities served as predictor variables.

For the second study population, between-group differences were compared using Chi Square testing with a significance level of $P<0.05$.
Pre- and post-BPA HCV Ab testing were compared using Chi-Square testing.

\section{RESULTS}

\section{Study Population 1}

The total study population comprised 106,753 subjects, 11,976 of whom underwent HCV-Ab testing and 670 tested positive. Table 1 shows a stratification of the patients according to their demographic characteristics.

Figure 1 shows the influence of demographic characteristics on the prevalence HCV-Ab testing. Testing was more frequent among patients within the age range of $50-64$ years as compared to patients aged $65-79$ years. Similarly, females were slightly more likely to be tested than males. Although statistically significant, these differences between the subgroups were small. More substantial differences were noted with regard to ethnicity and race, as African Americans, Asian, and Hispanic patients were more frequently tested than self-classified Causasians, American Indians, or Non-Hispanics. HCV-Ab testing was also more frequently performed in patients with a variety of comorbid conditions (Figure 2). The two conditions most frequently associated with HCV-Ab testing were HIV infection and chronic kidney disease. Table 2 shows the results of the multivariate analysis, using the presence of HCV antibody test as outcome variable and demographic characteristics

\begin{tabular}{lllll}
\hline Table 1: Demographics of Study Population 1 & & & \\
\hline $\begin{array}{l}\text { Demographic } \\
\text { characteristics }\end{array}$ & HCV AB tested & & $N$ & $(\%)$ \\
\hline Total & $N$ & $(\%)$ & 106,753 & $(100 \%)$ \\
Age & 11,976 & $(100 \%)$ & & \\
Average (SD) & & & 59.7 & $(5.9)$ \\
$50-64$ & 59.7 & $(5.8)$ & 79,198 & $(74 \%)$ \\
$65-79$ & 9,101 & $(76 \%)$ & 27,555 & $(26 \%)$ \\
Gender & 2,875 & $(24 \%)$ & & $(58 \%)$ \\
Female & & & 61,789 & $(42 \%)$ \\
Male & 7,056 & $(59 \%)$ & 44,964 & $(6 \%)$ \\
Race & 4,920 & $(41 \%)$ & & $(0 \%)$ \\
African American & 1,213 & $(10 \%)$ & 5,905 & $(4 \%)$ \\
American Indian & 30 & $(0 \%)$ & 271 & $(68 \%)$ \\
Asian & 705 & $(6 \%)$ & 4,531 & $(22 \%)$ \\
Caucasian & 7,419 & $(62 \%)$ & 72,154 & $(0 \%)$ \\
Other & 2,609 & $(22 \%)$ & 23,892 & $(4 \%)$ \\
Ethnicity & & & $(96 \%)$ \\
Unknown & 9 & $(0 \%)$ & 174 & \\
Hispanic/Latino & 658 & $(5 \%)$ & 4,252 & 102,327 \\
Non-Hispanic & 11,309 & $(94 \%)$ &
\end{tabular}



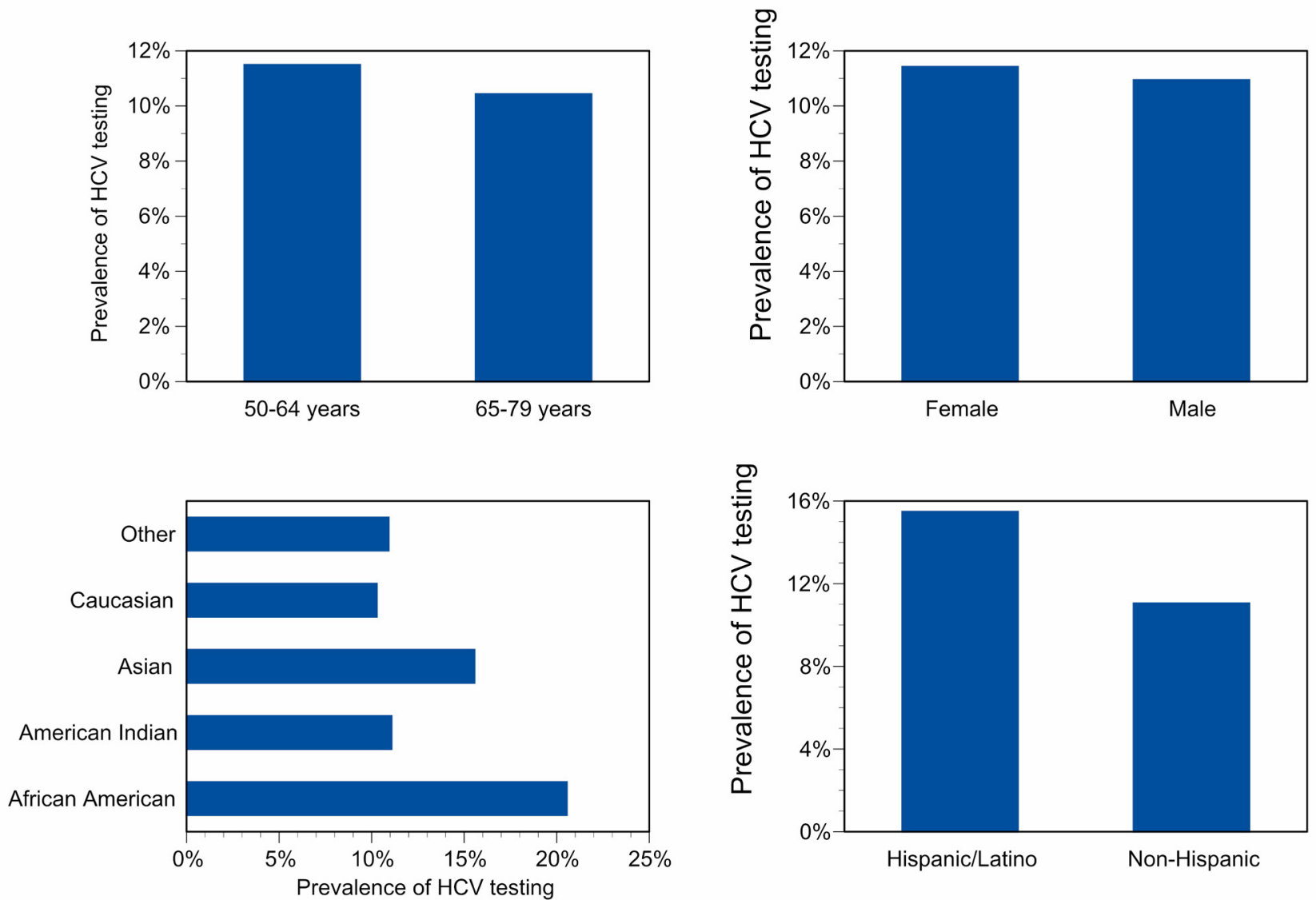

Figure 1: Influence of demographic characteristics on HCV antibody testing. Age, sex, race and ethnicity all exerted statistically significant influences.

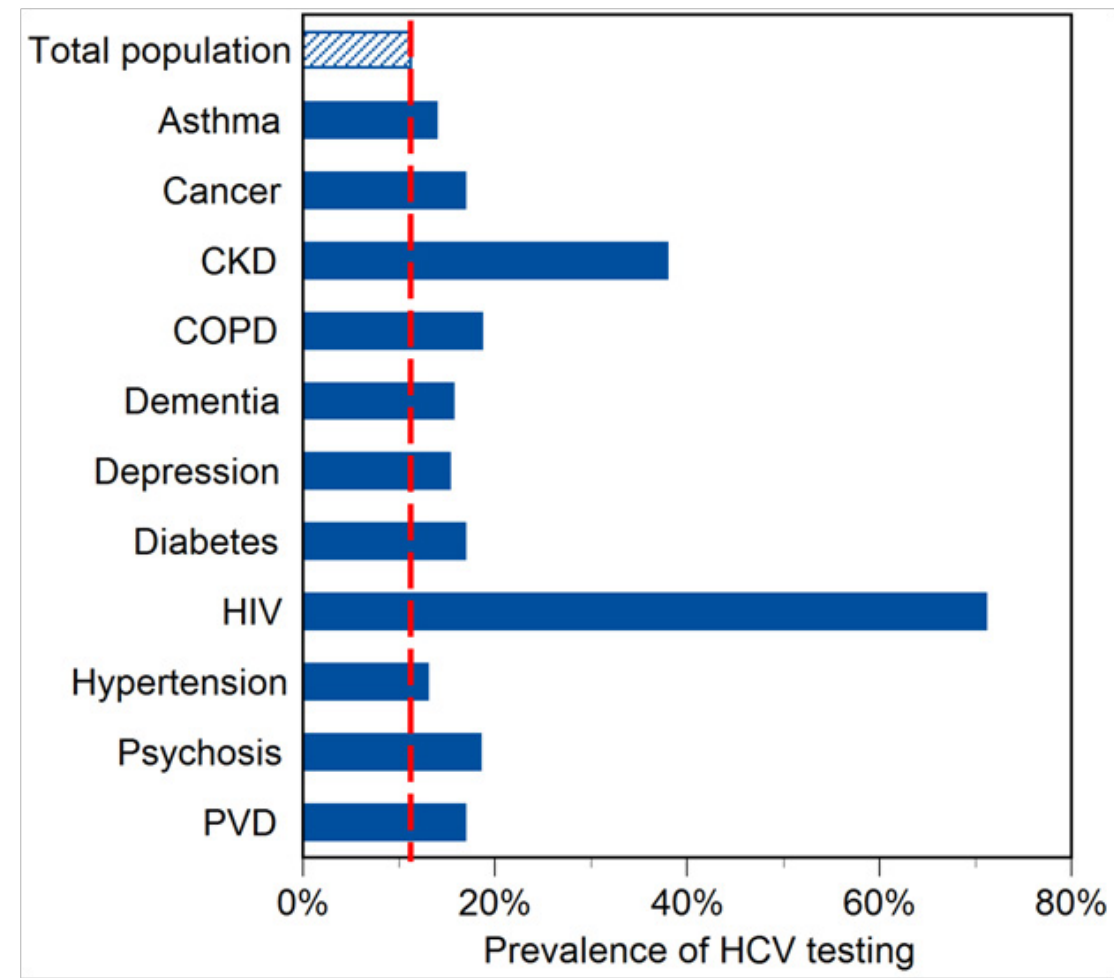

Figure 2: Influence of comorbid conditions on HCV antibody testing. Except for dementia, all comorbid conditions exerted a statistically significant influence. CKD: chronic kidney disease; COPD: chronic pulmonary obstructive disease; HIV: human immune deficiency virus infection; PVD: peripheral vascular disease. 


\begin{tabular}{|c|c|c|c|}
\hline Predictor variable & Odds ratio & 95\% Confidence interval & $P$-value \\
\hline \multicolumn{4}{|l|}{ Age-Sex } \\
\hline Younger age* & 1.20 & $(1.12-1.29)$ & $<0.0001$ \\
\hline Female & 0.94 & $(0.91-0.98)$ & 0.0035 \\
\hline \multicolumn{4}{|l|}{ Race } \\
\hline African American** & 1.96 & $(1.82-2.10)$ & $<0.0001$ \\
\hline American Indian & 1.00 & $(0.67-1.44)$ & 0.5836 \\
\hline Asian & 1.65 & $(1.51-1.79)$ & $<0.0001$ \\
\hline Other & 1.01 & $(0.96-1.06)$ & 0.6022 \\
\hline \multicolumn{4}{|l|}{ Ethnicity } \\
\hline Hispanic & 1.52 & $(1.38-1.66)$ & $<0.0001$ \\
\hline \multicolumn{4}{|l|}{ Comorbidity } \\
\hline Diabetes & 1.44 & $(1.36-1.52)$ & $<0.0001$ \\
\hline COPD & 1.55 & $(1.35-1.77)$ & $<0.0001$ \\
\hline Psychosis & 1.42 & $(1.01-1.95)$ & 0.0416 \\
\hline Dementia & 1.26 & $(0.72-2.08)$ & 0.4045 \\
\hline HIV & 16.77 & $(11.32-25.35)$ & $<0.0001$ \\
\hline CKD & 3.64 & $(3.15-4.21)$ & $<0.0001$ \\
\hline Cancer & 1.55 & $(1.33-1.80)$ & $<0.0001$ \\
\hline Depression & 1.50 & $(1.42-1.58)$ & $<0.0001$ \\
\hline Hypertension & 1.12 & $(1.07-1.17)$ & $<0.0001$ \\
\hline PVD & 1.21 & $(1.01-1.45)$ & 0.0352 \\
\hline Asthma & 1.18 & $(1.09-1.27)$ & $<0.0001$ \\
\hline
\end{tabular}

For the overall model: $N=106,751$, chi-square $=1,847(d f=18, P<0.0001)$. CKD: chronic kidney disease; COPD: chronic pulmonary obstructive disease; HIV: human immune deficiency virus disease; PVD: peripheral vascular disease. ${ }^{*}$ Per age change over entire range. ${ }^{* *}$ Caucasian serving as reference for all other races.

and comorbid conditions as predictor variables. The results of the multivariate analysis largely confirmed the results of the univariate analyses depicted in Figures 1 and 2. Figure 3 contains a comparison of the medical sub-specialties amongst all primary care physicians and amongst the physicians, who ordered the HCV antibody testing. Each subspecialty is expressed as percentage of all physicians providing primary care and as percentage of all ordered HCV tests. Internal Medicine and Family Medicine clinics performed most of the tests but were relatively underrepresented amongst the ordering physicians as compared to the subspecialists. High frequencies of test orders were associated with gastroenterology and rheumatology specialty clinics.

\section{Study Population 2}

In July 2015, 11797 baby boomers were seen in the NorthShore outpatient clinics. Over $97 \%$ of patients were seen in internal medicine and family medicine clinics, the remainder was seen in subspecialty clinics. Patients were predominantly female, and self-identified as Caucasians. There were no significant demographic differences between the three patient categories (Supplemental Table 1). A group of 1708 patients in this group underwent HCV$\mathrm{Ab}$ testing prior to the observation period, leaving 10089 patients who were eligible for one-time testing. As shown in Table 3, approximately half of the patients were tested solely on the basis of belonging to the birth-cohort. The remaining patients were tested because of known $\mathrm{HCV}$ risk factors, or during an evaluation for liver disease.

The specialty-specific rates of birth-cohort HCV screening were $0.82 \%$ (60 of 7303 ) in internal medicine, $0.28 \%$ (7 of 2490) in family medicine, and $0.67 \%$ (2 of 296) in subspecialty clinics.

\section{Impact of $\mathrm{HCV}-\mathrm{BPA}$ on age cohort testing}

$\mathrm{HCV}$ testing rates were increased from $0.68 \%(69 / 10,089)$ pre-BPA to $10.76 \%(5451 / 45188)$ during the four months following the system-wide implementation of the BPA, corresponding to a 15.8-fold increase (Figure 4). The difference between the two rates was statistically highly significant $(P<0.0001)$.

\section{DISCUSSION}

Our study highlights some of the challenges and limitations of HCV birth-cohort testing. While conceptually straightforward, the systematic implementation of testing in this high-risk group has been difficult to achieve in many 


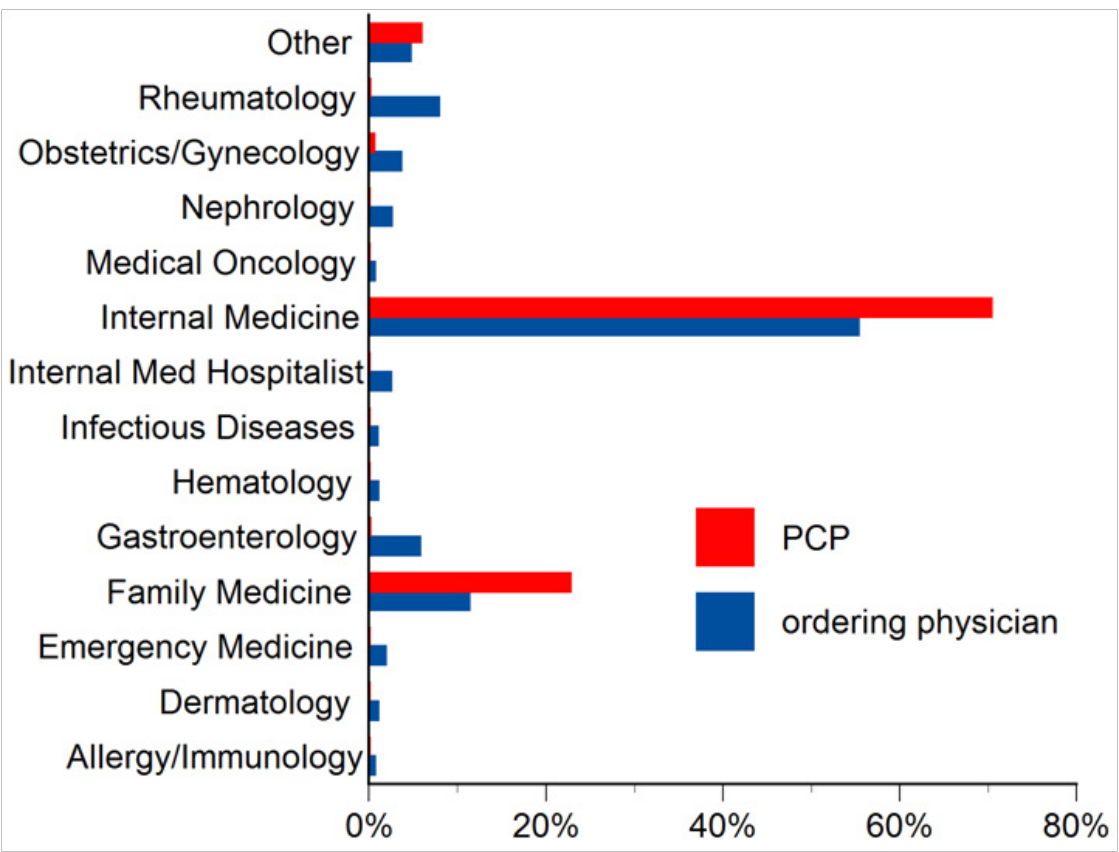

Figure 3: Comparison of medical sub-specialty amongst all primary care physicians (PCP) and amongst physicians ordering HCV antibody testing (chi-square 25277 , $d f=13, P<0.0001)$.

\begin{tabular}{lll}
\hline Table 3: HCV Ab testing rates in Study Population 2 \\
\hline Test indication & $\boldsymbol{N}$ & $(\%)$ \\
\hline Grand Total & 10,089 & $(100.00 \%)$ \\
Total HCV Ab - tested & 131 & $(1.30 \%)$ \\
Birth-cohort & 69 & $(0.68 \%)$ \\
Risk factor & 28 & $(0.28 \%)$ \\
Diagnostic & 34 & $(0.34 \%)$ \\
\hline
\end{tabular}

US healthcare systems, with the notable exception of the Veterans Associations HCV Initiative, which has resulted in screening rates of over $50 \% .^{[15]}$

In our population of over 100,000 commercially insured baby boomers, the overall HCV-Ab testing rate was $11.2 \%$, suggesting a modest but meaningful implementation of the current HCV screening guidelines.

However, a closer analysis of the data provided clear evidence that the historic testing rates were predominantly due to the presence of real or perceived risk factors, including ethnic and racial factors, comorbidities, and other medical and demographic features. Several of these factors have been previously reported. For example, disproportionately high screening rates in African-American and Hispanic patients were previously reported in a large patient cohort in Southeast Michigan, ${ }^{[16]}$ and in the Veterans Affairs patient cohort of over five million individuals. ${ }^{[17]}$ With regard to gender, testing rates in women have been found

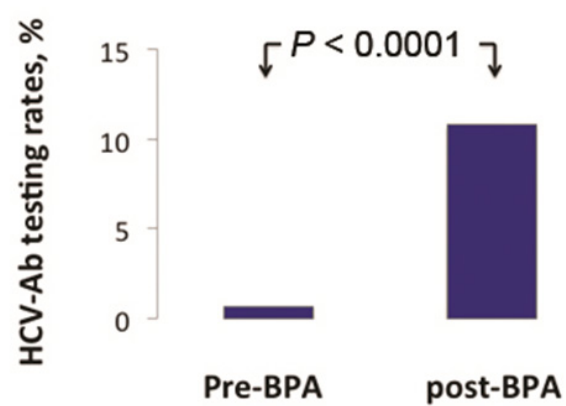

Figure 4: Comparison of HCV screening rates in age cohort patients before and after the implementation of an EMR-based BPA (chi-square 1033.32, $d f=1, P<0.0001$ ).

to be higher than in men in some ${ }^{[18]}$ but not all studies. ${ }^{[19,20]}$ The association of high testing rates in patients with HIV infection $^{[21]}$ and chronic renal disease ${ }^{[22]}$ are not surprising in view of the increased exposure risk in these groups. The modest but significant association with a number of other comorbidities, including diabetes, ${ }^{[23]}$ chronic pulmonary disease, ${ }^{[24]}$ psychiatric disease, ${ }^{[25]}$ cancer,${ }^{[26]}$ hypertension, ${ }^{[27]}$ may be related to possible extrahepatic manifestations of $\mathrm{HCV}$, or may reflect higher rates of healthcare utilization in patients with chronic diseases.

These confounding data prompted use to determine the true birth-cohort screening rates in our health care system. To this end, we analyzed all patients who presented to their primary care offices during the month of July, 2015. Of note, this date corresponded to a time period approximately three years after the recommendation for universal baby boomer screening by the CDC, and two years following the endorsement by the U.S. Preventive Services Task Force (USPSTF). 
Strikingly, only $1.3 \%$ of all eligible birth-cohort patients in this group underwent $\mathrm{HCV} \mathrm{Ab}$ testing, and the majority $(0.7 \%)$ of patients were tested based on the presence of risk factors or abnormal liver tests. Only $0.6 \%$ of patients underwent "true birth-cohort testing", more than one order of magnitude below the overall historic testing rate in institution.

Due to the small numbers of individuals tested, we were unable to perform a statistically meaningful comparison of testing rates by primary care, family practice, or medical subspecialty physicians. However, since primary care and family practice accounted for approximately $97 \%$ all patient visits, we can predict that a major improvement in $\mathrm{HCV}$ screening will require higher implementation rates in these two clinics. In comparison, the contribution of subspecialty clinics will be limited.

While sobering, our results are well within the range of comparable studies in the US. For example, Isenhour and colleagues recently reported an overall $\mathrm{HCV}$ Ab testing rate of only $3.26 \%$ in a population of over 24 million enrollees from Truven Health's MarkedScan Commercial and Medicare Supplemental insurance claims database. They noted a significant, $91 \%$ increase in testing rates between 2011 and 2014, but concluded that "testing remains suboptimal". ${ }^{[28]}$

The poor adherence to sensible and validated screening guidelines does not appear to be limited to HCV, but may be a general feature of primary care medicine. Multiple barriers to implementation have been identified. They include personal characteristics, guideline features, and external factors influencing the physician's decision in favor of or against screening at the point of care. ${ }^{[29]}$

Approaches to improve HCV screening rates have been widely discussed in the recent literature. They include the creative use of electronic medical record-based alerts. ${ }^{[30,31]}$ For example, Lok and colleagues recently reported the successful implementation of an electronic medical recordbased "Best Practice Alert". ${ }^{[32]}$ This alert automatically identified birth-cohort patients who had not been screened, and prompted the clinic physician to order the HCV Ab test at the point of care. This intervention, coupled with educational materials for patients and providers, increased screening rates approximately 10 -fold, from 7.6 to over 72 per cent. Similar improvements have been reported in a recent study by Klausner and colleagues. ${ }^{[33]}$ We used a similar approach by introducing a BPA into our healthcare system's EMR ("EPIC"), and observed a 15-fold increase in screening rates. Assuming a sustained testing rate of $10 \%$ per patient visit, and biannual primary care clinic visits for the majority of patients, the cumulative testing rate in our patient population would approach $65 \%$ over a 5 -year BPA span. Achieving a cumulative rate of $89 \%$ would require a doubling of the per-visit rate to $20 \%$, a target that we consider achievable.

In summary, our findings demonstrate that true birthcohort-based HCV testing is infrequently performed in our health care system. Our study highlights the suboptimal implementation of current HCV birth-cohort screening guidelines, and provides a rationale for quality improvement initiatives to address this important public health challenge.

\section{Source of Foundation}

The research reported in this manuscript was funded through an educational grant from Gilead Sciences Inc, ISR grant IN-US-342-4105.

\section{Conflict of Interest}

None declared.

\section{REFERENCES}

1. Ward JW. The epidemiology of chronic hepatitis $\mathrm{C}$ and one-time hepatitis C virus testing of persons born during 1945 to 1965 in the United States. Clin Liver Dis 2013;17:1-11.

2. Armstrong GL, Wasley A, Simard EP, McQuillan GM, Kuhnert WL, Alter MJ. The prevalence of hepatitis C virus infection in the United States, 1999 through 2002. Ann Intern Med 2006;144:705-14.

3. Asselah T, Marcellin P. Direct acting antivirals for the treatment of chronic hepatitis C: one pill a day for tomorrow. Liver Int 2012;32(Suppl 1):88102.

4. Denniston MM, Klevens RM, McQuillan GM, Jiles RB. Awareness of infection, knowledge of hepatitis $\mathrm{C}$, and medical follow-up among individuals testing positive for hepatitis C: National Health and Nutrition Examination Survey 2001-2008. Hepatology 2012;55:1652-61.

5. CDC. Recommendations for prevention and control of hepatitis $\mathrm{C}$ virus (HCV) infection and HCV-related chronic disease. MMWR 1998;47:139.

6. Roblin DW, Smith BD, Weinbaum CM, Sabin ME. HCV screening practices and prevalence in an MCO, 2000-2007. Am J Manag Care 2011;17:548-55.

7. Southern WN, Drainoni ML, Smith BD, Christiansen CL, McKee D, Gifford $\mathrm{AL}$, et al. Hepatitis $\mathrm{C}$ testing practices and prevalence in a high-risk urban ambulatory care setting. J Viral Hepat 2011;18:474-81.

8. Spradling PR, Rupp L, Moorman AC, Lu M, Teshale EH, Gordon SC, et al. Hepatitis $\mathrm{B}$ and $\mathrm{C}$ virus infection among 1.2 million persons with access to care: factors associated with testing and infection prevalence. Clin Infect Dis 2012;55:1047-55.

9. Recommendations for the Identification of Chronic Hepatitis C Virus Infection Among Persons Born During 1945-1965. MMWR 2012; 61(RR04): 1-18.

10. Rein DB, Smith BD, Wittenborn JS, Lesesne SB, Wagner LD, Roblin DW, et al. The cost-effectiveness of birth-cohort screening for hepatitis $\mathrm{C}$ antibody in U.S. primary care settings. Ann Intern Med 2012;156:263-70.

11. Moyer VA, Force USPST. Screening for hepatitis $C$ virus infection in adults: U.S. Preventive Services Task Force recommendation statement. Ann Intern Med 2013;159:349-57. 
12. Linas BP, Hu H, Barter DM, Horberg M. Hepatitis C screening trends in a large integrated health system. Am J Med 2014;127:398-405.

13. Sidlow R, Msaouel P. Improving Hepatitis C Virus Screening Rates in Primary Care: A Targeted Intervention Using the Electronic Health Record. J Healthc Qual 2015;37:319-23.

14. Shahnazarian V, Karu E, Mehta P. Hepatitis C: improving the quality of screening in a community hospital by implementing an electronic medical record intervention. BMJ Qual Improv Rep 2015;4: u208549. w3409.

15. Sarkar S, Esserman DA, Skanderson M, Levin FL, Justice AC, Lim JK. Disparities in hepatitis C testing in U.S. veterans born 1945-1965. J Hepatol 2016;65:259-65.

16. Bourgi K, Brar I, Baker-Genaw K. Health Disparities in Hepatitis C Screening and Linkage to Care at an Integrated Health System in Southeast Michigan. PLoS One 2016;11:e0161241.

17. Backus LI, Belperio PS, Loomis TP, Mole LA. Impact of race/ethnicity and gender on HCV screening and prevalence among U.S. veterans in Department of Veterans Affairs Care. Am J Public Health 2014;104(Suppl 4):S555-61.

18. Linas BP, Barter DM, Leff JA, Assoumou SA, Salomon JA, Weinstein MC, et al. The hepatitis $\mathrm{C}$ cascade of care: identifying priorities to improve clinical outcomes. PLoS One 2014;9:e97317.

19. Shatin D, Schech SD, Patel K, McHutchison JG. Population-based hepatitis $\mathrm{C}$ surveillance and treatment in a national managed care organization. Am J Manag Care 2004;10:250-6.

20. Cook N, Turse EP, Garcia AS, Hardigan P, Amofah SA. Hepatitis C Virus Infection Screening Within Community Health Centers. J Am Osteopath Assoc 2016;116:6-11.

21. Taylor LE, Swan T, Mayer KH. HIV coinfection with hepatitis C virus: evolving epidemiology and treatment paradigms. Clin Infect Dis 2012;55(Suppl 1):S33-42.

22. Cacoub P, Desbois AC, Isnard-Bagnis C, Rocatello D, Ferri C. Hepatitis $\mathrm{C}$ virus infection and chronic kidney disease: Time for reappraisal. J Hepatol 2016;65(1 Suppl):S82-94.

23. Hammerstad SS, Grock SF, Lee HJ, Hasham A, Sundaram N, Tomer Y. Diabetes and Hepatitis C: A Two-Way Association. Front Endocrinol (Lausanne) 2015;6:134.
24. Silva DR, Stifft J, Cheinquer H, Knorst MM. Prevalence of hepatitis C virus infection in patients with COPD. Epidemiol Infect 2010;138:167-73.

25. Rosenberg SD, Goodman LA, Osher FC, Swartz MS, Essock SM, Butterfield MI, et al. Prevalence of HIV, hepatitis B, and hepatitis $C$ in people with severe mental illness. Am J Public Health 2001;91:31-7.

26. Qadwai S, Rehman T, Barsa J, Solangi Z, Lebovics E. Hepatitis C Virus and Nonliver Solid Cancers: Is There an Association between HCV and Cancers of the Pancreas, Thyroid, Kidney, Oral Cavity, Breast, Lung, and Gastrointestinal Tract? Gastroenterol Res Pract 2017;2017:8349150.

27. Cacoub P, Gragnani L, Comarmond C, Zignego AL. Extrahepatic manifestations of chronic hepatitis C virus infection. Dig Liver Dis 2014;46(Suppl 5):S165-73.

28. Isenhour CJ, Hariri SH, Hales CM, Vellozzi CJ. Hepatitis C Antibody Testing in a Commercially Insured Population, 2005-2014. Am J Prev Med 2017;52:625-31.

29. Fischer F, Lange K, Klose K, Greiner W, Kraemer A. Barriers and Strategies in Guideline Implementation-A Scoping Review. Parthasarathy S, ed. Healthcare (Basel) 2016;4:36.

30. Golden MR, Duchin J, Chew LD, Huntington JH, Sugg N, Jackson S, et al. Impact of an Electronic Medical Record-Based System to Promote Human Immunodeficiency Virus/Hepatitis C Virus Screening in Public Hospital Primary Care Clinics. Open Forum Infect Dis 2017;4:ofx075.

31. Goel A, Sanchez J, Paulino L, Feuille C, Arend J, Shah B, et al. A systematic model improves hepatitis $\mathrm{C}$ virus birth cohort screening in hospital-based primary care. J Viral Hepat 2017;24:477-85.

32. Konerman MA, Thomson M, Gray K, Moore M, Choxi H, Seif E, et al. Impact of an Electronic Health Record Alert in Primary Care on Increasing Hepatitis C Screening and Curative Treatment for Baby Boomers. Hepatology 2017;66:1805-13.

33. Castrejon M, Chew KW, Javanbakht M, Humphries R, Saab S, Klausner JD. Implementation of a Large System-Wide Hepatitis C Virus Screening and Linkage to Care Program for Baby Boomers. Open Forum Infect Dis 2017;4:ofx109.

How to cite this article: Yeboah-Korang $A$, Beig MI, Khan MQ, Goldstein JL, Macapinlac DM, Maurer D, et al. Hepatitis C screening in commercially insured U.S. birth-cohort patients: Factors associated with testing and effect of an EMR-based screening alert J Transl Intern Med 2018; 6: 82-9.

\begin{tabular}{|c|c|c|c|c|c|c|c|c|}
\hline \multicolumn{9}{|c|}{ Supplemental Table 1: Demographics of Study Population 2} \\
\hline \multirow{2}{*}{$\begin{array}{l}\text { Demographic } \\
\text { characteristics }\end{array}$} & \multicolumn{2}{|c|}{ Internal medicine } & \multicolumn{2}{|c|}{ Family medicine } & \multicolumn{2}{|c|}{ Subspecialties } & \multicolumn{2}{|c|}{ Grand total } \\
\hline & $N$ & $(\%)$ & $N$ & $(\%)$ & $N$ & $(\%)$ & $N$ & $(\%)$ \\
\hline Total & 8,610 & $(100 \%)$ & 2,861 & $(100 \%)$ & 326 & $(100 \%)$ & 11,797 & $(100 \%)$ \\
\hline \multicolumn{9}{|l|}{ Age } \\
\hline$<65$ years & 5,682 & $(66 \%)$ & 2,167 & $(76 \%)$ & 256 & (79\%) & 8,105 & $(69 \%)$ \\
\hline$\geq 65$ years & 2,928 & $(34 \%)$ & 694 & $(24 \%)$ & 70 & $(21 \%)$ & 3,692 & $(31 \%)$ \\
\hline \multicolumn{9}{|l|}{ Gender } \\
\hline Female & 5,316 & $(62 \%)$ & 1,634 & $(57 \%)$ & 240 & $(74 \%)$ & 7,190 & $(61 \%)$ \\
\hline Male & 3,294 & $(38 \%)$ & 1,227 & $(43 \%)$ & 86 & $(26 \%)$ & 4,607 & $(39 \%)$ \\
\hline \multicolumn{9}{|l|}{ Race/Ethnicity } \\
\hline Caucasian & 6,012 & $(70 \%)$ & 1,851 & $(65 \%)$ & 224 & $(69 \%)$ & 8,087 & $(69 \%)$ \\
\hline African American & 541 & $(6 \%)$ & 272 & $(10 \%)$ & 15 & $(5 \%)$ & 828 & $(7 \%)$ \\
\hline Hispanic & 281 & $(3 \%)$ & 225 & $(8 \%)$ & 19 & $(6 \%)$ & 525 & $(4 \%)$ \\
\hline Asian & 344 & $(4 \%)$ & 142 & $(5 \%)$ & 17 & $(5 \%)$ & 503 & $(4 \%)$ \\
\hline Other & 1,432 & $(17 \%)$ & 371 & $(13 \%)$ & 51 & $(16 \%)$ & 1,854 & $(16 \%)$ \\
\hline
\end{tabular}

